\title{
Óleos essenciais de Cymbopogon nardus, Cinnamomum zeylanicum e Zingiber officinale: composição, atividades antioxidante e antibacteriana $^{1}$
}

\author{
Essential oils of Cinnamomum zeylanicum, Cymbopogon nardus and Zingiber \\ officinale: composition, antioxidant and antibacterial activities
}

\author{
Milene Aparecida Andrade ${ }^{2}$, Maria das Graças Cardoso ${ }^{2 *}$, Luís Roberto Batista ${ }^{3}$, Aline Cristina Teixeira Mallet ${ }^{3}$ \\ e Samísia Maria Fernandes Machado ${ }^{4}$
}

\begin{abstract}
Resumo - Objetivou-se neste estudo caracterizar quimicamente e avaliar as atividades antioxidante e antibacteriana dos óleos essenciais de citronela (Cymbopogon nardus), canela (Cinnamomum zeylanicum) e gengibre (Zingiber officinale). A obtenção do óleo essencial foi realizada utilizando a técnica de hidrodestilação por meio do aparelho de Clevenger modificado e a identificação e quantificação dos constituintes pelas análises em CG/EM e CG-DIC. A avaliação da atividade antibacteriana foi realizada por meio da técnica difusão cavidade em ágar, utilizando os microrganismos Staphylococcus aureus ATCC 6538, Listeria monocytogenes ATCC 19117, Escherichia coli ATCC 11229, Salmonella Cholerasuis ATCC 6539 e Pseudomonas aeruginosa ATCC 15442. A atividade antioxidante foi avaliada utilizando sistema $\beta$-caroteno/ácido linoléico e o método de seqüestro de radicais DPPH. Nas análises cromatográficas, os constituintes majoritários encontrados no óleo essencial de C. nardus foram citronelal (47,12\%), geraniol (18,56\%) e citronelol (11,07\%), no óleo essencial de C. zeylanicum foram identificados (E)- cinamaldeído (77,72\%), acetato de (E)-cinamila (5,99\%) e o monoterpenóide 1,8-cineol (4,66\%) e, para $Z$. officinale os majoritários foram geranial $(25,06 \%)$, neral $(16,47 \%), 1,8$-cineol $(10,98 \%)$, geraniol $(8,51 \%)$, acetato de geranila $(4,19 \%)$ e o canfeno $(4,30 \%)$. Os óleos essenciais apresentaram atividade antibacteriana tanto para bactérias Gram-negativas como para bactérias Gram-positivas, sendo que o óleo essencial de $C$. zeylanicum foi o mais eficiente. A atividade antioxidante foi evidenciada pelo teste $\beta$-caroteno/ácido linoléico, respectivamente, para $C$. nardus, seguido de $Z$. officinale e $C$. zeylanicum, e pelo teste do DPPH foi observada apenas para C. nardus.
\end{abstract}

Palavras-chave - Citronela. Canela. Gengibre. Essências.

\begin{abstract}
The aims of this study were to chemically characterize and to evaluate the antioxidant and antibacterial activities of the citronella (Cymbopogon nardus), cinnamon (Cinnamomum zeylanicum) and ginger (Zingiber officinale) essential oils. The essential oil extraction was performed by the using of hydrodistillation through the modified Clevenger apparatus, and identification and quantification of the constituents by the GC/MS and GC-FID analysis. Evaluation of antibacterial activity was performed by using agar well diffusion method, with Staphylococcus aureus ATCC 6538, Listeria monocytogenes ATCC 19117, Escherichia coli ATCC 11229, Salmonella Cholerasuis ATCC 6539 and Pseudomonas aeruginosa ATCC 15442. The antioxidant activity was evaluated by using $\beta$-carotene/linoleic acid system and the radical scavenging DPPH method. In chromatographic analysis the major constituents of C. nardus essential oil were citronellal (47.12\%), geraniol (18.56\%) and citronellol (11.07\%), in the C. zeylanicum essential oil were identified (E)-cinnamaldehyde (77.72\%), acetate (E)-cinnamyl (5.99\%) and the monoterpenoid 1,8-cineole $(4.66 \%)$ as major components, and in Z. officinale the majority were geranial $(25.06 \%)$, neral $(16.47 \%), 1,8$-cineole $(10.98 \%)$, geraniol $(8.51 \%)$, geranyl acetate $(4.19 \%)$ and camphene $(4.30 \%)$. The essential oils showed antibacterial activity for both Gram-negative and Gram-positive microorganisms, and the most efficient was $C$. zeylanicum essential oil. The antioxidant activity was observed, when using $\beta$-carotene/ linoleic acid system, for $C$. nardus, followed by Z. officinale and C. zeylanicum and, when using DPPH test, activity was observed only for C. nardus.
\end{abstract}

Key words - Citronella. Cinnamon. Ginger. Essences.

\footnotetext{
* Autor para correspondência

${ }^{1}$ Recebido para publicação em 22/09/2010; aprovado em 13/10/2011

Parte da Dissertação de Mestrado do primeiro autor, apresentada ao Programa de Pós-Graduação em Agroquímica, DQI/UFLA ${ }^{2}$ Departamento de Química, DQI/UFLA, Lavras-MG, Brasil, 37.200-000, mileneaandrade@hotmail.com, mcardoso@dqi.ufla.br ${ }^{3}$ Departamento de Ciência dos Alimentos, DCA/UFLA, Lavras-MG, Brasil, 37.200-000, luisrb@dca.ufla.br, a.mallet@ig.com.br ${ }^{4}$ Departamento de Química, DQI/UFS, São Cristovão-SE, Brasil, 49.100-000, samisia@ufs.br
} 


\section{Introdução}

A determinação da atividade biológica de plantas e seus derivados são muito importantes para a área de produtos naturais. Os óleos essenciais, metabólitos secundários voláteis que se caracterizam por serem misturas complexas de compostos orgânicos, são cada vez mais estudados como antioxidantes e para o controle de micro-organismos. Eles ocupam um lugar preponderante nas indústrias de insumos farmacêuticos, agroalimentícias, perfumaria e cosméticos, devido não somente na possibilidade de obtenção de compostos aromáticos (odor agradável), mas também de compostos com propriedades terapêuticas, e de proteção contra os processos de oxidação e deterioração por microrganismos (BAKKALI et al., 2008; BURT, 2004; SINGH et al., 2007).

Os principais micro-organismos envolvidos nos processos de contaminações de alimentos são as bactérias, pois atuam sobre numerosos tipos de substratos, com diferentes temperaturas, $\mathrm{pH}$, e condições do meio ambiente. Tendo em vista aos problemas de resistência de microorganismos a antibióticos e desinfetantes convencionais, e diante da atual tendência do mercado de utilizar produtos ecologicamente seguros, o emprego de óleos essenciais para a conservação de alimentos e controle fitossanitário vem sendo muito estudado, propiciando o desenvolvimento de técnicas que procuram reduzir os efeitos negativos de oxidantes, radicais e micro-organismos causadores de grandes prejuízos às indústrias alimentícias (PEREIRA et al., 2008; SACCHETTI, 2004).

$\mathrm{Na}$ indústria de alimentos, os antioxidantes sintéticos mais utilizados para controlar a oxidação lipídica são os compostos fenólicos butil-hidroxi-anisol (BHA), 2,6-di-tert-butil-4-hidroxitolueno (BHT), tercbutil-hidroquinona (TBHQ) e galato de propila (PG), porém estudos relacionados com a toxicologia desses compostos têm demonstrado a possibilidade destes apresentarem efeito carcinogênico em experimentos com animais. Assim, o uso destas substâncias como antioxidantes é restringido em vários países, muitas pesquisas têm sido desenvolvidas com o intuito de encontrar produtos naturais destinados a esta finalidade, que permitirão a substituição dos sintéticos ou fazer associações entre eles, com a finalidade de diminuir sua quantidade nos alimentos. Condimentos vegetais e seus derivados têm sido usados para evitar a oxidação dos alimentos, bem como para combater os radicais livres (DORMAN et al., 2000; RAMALHO; JORGE, 2006; RUBERTO; BARATTA, 2000).

Devido à importância de plantas como condimentos e seu potencial em terapias biológicas, com base nas propriedades relatadas, objetivou-se nesse estudo caracterizar quimicamente os óleos essenciais de
Cymbopogon nardus (capim-citronela), Cinnamomum zeylanicum (canela) e Zingiber officinale (gengibre), e avaliar as suas possíveis atividades antioxidante e antibacteriana.

\section{Material e métodos}

\section{Material vegetal}

As plantas, C. zeylanicum e Z. officinale foram adquiridas em estabelecimentos comerciais da cidade de Lavras-MG, Brasil, e C. nardus foi coletada no Horto de Plantas Medicinais da UFLA, no dia 03 de março de 2009, às 8 horas da manhã, um dia ameno e sem precipitação. A cidade de Lavras localiza-se no sul do estado de Minas Gerais (Brasil), 21 ${ }^{\circ} 14^{\prime}$ S, longitude $45^{\circ} 00^{\prime}$ ' W Gr. e $918 \mathrm{~m}$ de altitude. As partes utilizadas das plantas foram cascas do tronco secas para C. zeylanicum, rizomas para Z. officinale e folhas frescas C. nardus.

Para obtenção do óleo essencial empregouse a técnica de hidrodestilação, utilizando-se um aparelho de Clevenger modificado, destilando-se por 2,5 horas (GUIMARÃES et al., 2008). O hidrolato foi centrifugado em centrífuga de cruzeta horizontal a $965,36 \mathrm{~g}$ por cinco minutos. O óleo essencial obtido foi armazenado em vidro âmbar e mantido sob refrigeração.

\section{Caracterização química e quantificação dos constituintes do óleo essencial}

A avaliação qualitativa do óleo essencial foi realizada por cromatografia em fase gasosa acoplada à espectrometria de massa (CG/EM - Shimadzu, modelo QP 5050A), sob as seguintes condições experimentais: coluna capilar de sílica fundida $(30 \mathrm{~m} \mathrm{x} \mathrm{0,25} \mathrm{mm)} \mathrm{com}$ fase ligada DB5 (0,25 $\mu \mathrm{m}$ de espessura de filme); He como

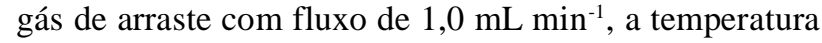
foi programada mantendo $50^{\circ} \mathrm{C}$ por $1,5 \mathrm{~min}$, seguindo de um aumento de $4{ }^{\circ} \mathrm{C} \mathrm{min}{ }^{-1}$ até atingir $200{ }^{\circ} \mathrm{C}$, depois a $10{ }^{\circ} \mathrm{C}$ até atingir $250{ }^{\circ} \mathrm{C}$ mantendo-se constante esta temperatura por $5 \mathrm{~min}$; t temperatura do injetor: $250^{\circ} \mathrm{C}$ e temperatura do detector (ou interface) de $280^{\circ} \mathrm{C}$; o volume da amostra injetada foi de $0,5 \mu \mathrm{L}$ em acetato de etila; taxa de partição do volume injetado de 1:100 e pressão na coluna de $64,20 \mathrm{kPa}$.

As condições do espectrômetro de massas foram: detector de varredura 1.000; intervalo de varredura de 0,50 fragmentos e fragmentos detectados na faixa de 40 a 500 Da. A identificação dos constituintes foi realizada com base na comparação dos índices de retenção da 
literatura (ADAMS, 2007). Para o índice de retenção foi utilizada a equação de Van den Dool e Kratz 1963 em relação à série homóloga de n-alcanos $\left(\mathrm{nC}_{8}-\mathrm{nC}_{18}\right)$ e fazendo extrapolação para $\mathrm{C}_{19}$ e $\mathrm{C}_{20}$. Também foram utilizadas duas bibliotecas do equipamento NIST107 e NIST21 que permitem a comparação dos dados dos espectros com aqueles existentes nas bibliotecas.

$\mathrm{Na}$ avaliação quantitativa utilizou-se um cromatógrafo gasoso Shimadzu CG-17A equipado com detector por ionização de chamas (DIC), nas seguintes condições experimentais: coluna capilar DB5; programação da coluna: temperatura inicial de $40{ }^{\circ} \mathrm{C}$ até $240{ }^{\circ} \mathrm{C}$; temperatura do injetor: $220{ }^{\circ} \mathrm{C}$; temperatura de detector: $240{ }^{\circ} \mathrm{C}$; gás carreador: nitrogênio $\left(2,2 \mathrm{~mL} \mathrm{~min}^{-1}\right)$; taxa de split 1:10; volume injetado: $1 \mu \mathrm{L}(1 \%$ de solução em diclorometano) e pressão na coluna de $115 \mathrm{kPa}$, sendo a quantificação de cada constituinte obtida por meio de normalização de áreas (\%).

\section{Atividade antioxidante}

A atividade antioxidante foi avaliada perante o consumo do radical DPPH e a oxidação do sistema $\beta$ caroteno/ácido linoléico. Cada ensaio foi realizado três vezes sendo calculada a média dos resultados.

\section{Capacidade de seqüestrar o radical livre DPPH}

A avaliação da atividade antioxidante diante do consumo de DPPH foi realizada de acordo com as metodologias de Sousa et al. (2007) e Lopes-Lutz et al. (2008) com algumas modificações.

Foi preparada uma solução metanólica de DPPH na concentração de $40 \mu \mathrm{g} \mathrm{mL} \mathrm{L}^{-1}$. Os óleos essenciais foram diluídos em metanol nas concentrações $(500 ; 300 ; 100 ; 50$; $25 ; 10 ; 5 \mu \mathrm{g} \mathrm{mL}^{-1}$ ). Para a avaliação, foram adicionados em um tubo de ensaio $2,7 \mathrm{~mL}$ da solução estoque de DPPH, seguido da adição de $0,3 \mathrm{~mL}$ da solução de óleo essencial. Paralelamente, foi preparado o branco, sendo este uma mistura de $2,7 \mathrm{~mL}$ de metanol e a solução metanólica dos compostos avaliados. Após 60 minutos foram realizadas leituras em espectrofotômetro (Shimadzu UV-160 1 PC) no comprimento de onda de $515 \mathrm{~nm}$ (TEPE et al., 2005). A atividade antioxidante foi calculada de acordo com Sousa et al. (2007).

Para a obtenção da $\mathrm{CI}_{50}$, foram plotados gráficos com os valores de \% I do DPPH versus as concentrações analisadas. Para fins de comparação foram testados os padrões timol e ácido ascórbico, por possuírem atividade antioxidante reconhecida. A curva analítica foi construída utilizando as concentrações $50 ; 25 ; 10$; $5 ; 2,5 ; 1 \mu \mathrm{g} \mathrm{mL}^{-1}$ para o ácido ascórbico e para o timol utilizou-se as mesmas concentrações dos óleos.

\section{Sistema $\beta$-caroteno/ácido linoléico}

A avaliação da atividade antioxidante utilizando o ensaio do $\beta$-caroteno/ácido linoléico foi realizada de acordo com as metodologias apresentadas por Kulisic et al. (2004) e Lopes-Lutz et al. (2008) com pequenas modificações.

Preparou-se solução de $\beta$-caroteno em clorofórmio $\left(0,3 \mu \mathrm{g} \mathrm{mL}^{-1}\right)$, após adicionou-se $60 \mu \mathrm{L}$ de ácido linoléico, $600 \mathrm{mg}$ de Tween $20 \AA$ e $1,5 \mathrm{~mL}$ de clorofórmio, sendo o clorofórmio evaporado em rotaevaporador. Posteriormente, $150 \mathrm{~mL}$ de água destilada saturada com oxigênio foram acrescidos na mistura sob agitação constante (emulsão A). Em seguida $2,8 \mathrm{~mL}$ da emulsão A foram colocados em tubos de ensaio e sob estas foram acrescidos $200 \mu \mathrm{L}$ das soluções metanólicas dos compostos na concentração de $500 \mathrm{mg} \mathrm{L}^{-1}$. Paralelamente, foram preparadas duas soluções, uma sem o antioxidante (testemunha absoluta), e outra com os mesmos reagentes de A, sem o $\beta$-caroteno (emulsão B - branco).

As leituras das amostras foram realizadas no tempo 0, em seguida os tubos foram incubados a $50{ }^{\circ} \mathrm{C}$ para a reação de oxidação e a leitura da absorbância foi medida após um intervalo de 60 minutos. Todas as leituras foram realizadas em triplicata.

A atividade antioxidante foi expressa como porcentagem de inibição após 60 minutos de incubação de acordo com Kulisic et al. (2004).

Para a obtenção da $\mathrm{CI}_{50}$, foram plotados gráficos como os valores de \% I da degradação do $\beta$ caroteno versus as concentrações analisadas. Para fins de comparação foram testados, os padrões, timol e ácido ascórbico, por possuírem atividade antioxidante reconhecida. As curvas analíticas dos padrões foram construídas utilizando-se as mesmas concentrações utilizadas para os óleos essenciais.

\section{Ensaios biológicos}

As bactérias utilizadas foram Staphylococcus aureus ATCC 6538, Listeria monocytogenes ATCC 19117, Escherichia coli ATCC 11229, Salmonella Cholerasuis ATCC 6539 e Pseudomonas aeruginosa ATCC 15442. Estas foram repicadas em caldo BHI, e ficaram incubadas a $37{ }^{\circ} \mathrm{C}$ por 24 horas. Posteriormente, alíquotas desse meio foram transferidas para um tubo com $5 \mathrm{~mL}$ de caldo de soja triptica (TSB). Os tubos foram incubados a $37{ }^{\circ} \mathrm{C}$ até alcançar a turbidez de uma solução padrão McFarland de 0,5, resultando numa suspensão contendo $10^{8} \mathrm{UFC} \mathrm{mL} \mathrm{mL}^{-1}$. As leituras de turbidez foram realizadas utilizando espectrofotômetro (Shimadzu UV-160 1PC), no comprimento de onda de $625 \mathrm{~nm}$ (NCCLS, 2003). 
A concentração de inóculo obtida pela escala McFarland de 0,5 (10 $\left.\mathrm{UFC}^{-1}\right)$ foi diluída até atingir a concentração de $10^{6} \mathrm{UFC} \mathrm{mL}^{-1}$, sendo esta transferida para o meio de cultura TSA, para as espécies L.monocytogenes, e para as demais espécies, transferida para o Ágar MuellerHinton. O ágar no qual foi inoculada a cultura bacteriana foi depositado sobre uma camada do mesmo ágar onde foram feitos os poços de deposição do óleo com o auxílio de pérolas de vidro. Estes foram preenchidos com $10 \mu \mathrm{L}$ das concentrações $(500 ; 250 ; 125 ; 62,5 ; 31,25 ; 15,62$; 7,$81 ; 3,90,1,95$ e $\left.0 \mu \mathrm{g} \mathrm{mL} \mathrm{m}^{-1}\right)$ do óleo essencial diluídos em dimetilsulfóxido (DMSO). As placas foram incubadas em BOD $37^{\circ} \mathrm{C}$ por 24 horas e medidos os diâmetros dos halos de inibição formados. Foram realizadas três repetições para cada tratamento, uma testemunha relativa com a aplicação de $10 \mu \mathrm{L}$ de DMSO, como padrão de comparação utilizou-se uma solução de $100 \mu \mathrm{g} \mathrm{mL}^{-1}$ do antibiótico Cloranfenicol (CL) (PEREIRA et al., 2008).

A partir dos diâmetros obtidos pode-se avaliar o perfil de sensibilidade das bactérias frente as diferentes concentrações dos óleos essenciais. A concentração mínima inibitória (CMI) foi definida como a menor concentração de óleo essencial que ocorreu a presença de halo de inibição.

\section{Resultados e discussão}

\section{Identificação e quantificação dos constituintes dos óleos essenciais}

\section{Cymbopogon nardus (Capim-citronela)}

Pelos dados descritos na Tabela 1, observa-se que foram identificados 17 constituintes presentes no óleo essencial de Cymbopogon nardus, sendo os componentes majoritários os monoterpenos acíclicos, citronelal $(47,12 \%)$, geraniol $(18,56 \%)$, e citronelol $(11,07 \%)$.

Oliveira et al. (2010), estudando o óleo essencial de C. nardus, encontraram como componentes majoritários, citronelal $(34,60 \%)$, geraniol $(23,17 \%)$ e citronelol $(12,09 \%)$, corroborando com os dados desse trabalho, porém os constituintes minoritários como o $\beta$-elemeno, $\delta$-cadineno, $\alpha$-muuroleno e neo-isopulegol, não foram encontrados nesse estudo. Anteriormente, Malele et al. (2007), avaliando a composição do óleo essencial de capim citronela encontraram resultados diferentes daqueles encontrados nesse estudo. Os autores observaram a presença de linalol $(27,4 \%)$, citronelol $(10,9 \%)$, geraniol $(8,5 \%)$, cis-calameneno $(4,3 \%), \beta$ elemeno $(3,9 \%)$ dentre outros compostos.

Esse tipo de diferença na composição e a concentração dos componentes dos óleos essenciais, de plantas de mesma espécie, podem variar devido a fatores ecológicos e as condições edafoclimáticas. De acordo com Marco et al. ( 2007), os componentes do óleo essencial de citronela são afetados pela época de coleta e espaçamento entre as plantas, onde o teor de geraniol foi superior em plantas colhidas quatro meses após o plantio, porém não houve influência do espaçamento e de altura de corte sobre este, concordando assim com os resultado obtidos por Blank et al. (2007), que reportaram que os componentes do óleo essencial de citronela foram alterados conforme a estação do ano e secagem, mas não variaram pelo horário de colheita.

\section{Cinnamomum zeylanicum (Canela)}

No óleo essencial da casca seca de Cinnamomum zeylanicum foram identificados 14 constituintes (TAB. 2), sendo que os fenilpropanóides (E)- cinamaldeído (77,72\%), acetato de (E)-cinamila $(5,99 \%)$ e o monoterpenóide 1,8 cineol $(4,66 \%)$, foram encontrados como componentes majoritários.

Pesquisas de Singh et al. (2007), com C. zeylanicum verificaram a presença de 13 componentes no seu óleo essencial, sendo que (E)-cinamaldeído $(97,7 \%)$ foi encontrado como o principal, seguido do $\delta$ cadineno $(0,9 \%), \alpha$-copaeno e $(0,8 \%)$ and $\alpha$-amorfeno $(0,5 \%)$. Estes dados concordam com os obtidos nesse estudo em relação ao elevado teor de (E)-cinamaldeído na composição do óleo essencial das cascas de canela.

Em estudos realizados com outras partes da planta, Lima et al. (2005), encontraram 23 constituintes no óleo essencial das folhas de canela, dos quais o eugenol se apresentou como o componente majoritário (60\%). No óleo essencial dos galhos foram identificados 36 compostos, com predominância dos monoterpenos $\alpha$ - e $\beta$-pineno $(9,9 \% ; 3,5 \%), \alpha$-felandreno $(9,2 \%), \rho$-cimeno $(6,2 \%)$, limoneno $(7,9 \%)$, linalol $(10,6 \%)$; os sesquiterpenos $\alpha$-copaeno $(3,3 \%),(\beta)$-cariofileno $(6,7 \%)$, óxido de cariofileno $(3,1 \%)$ e os alilbenzenos (E)-cinamaldeído $(7,8 \%)$ e acetato de (E)-cinamila $(9,7 \%)$. Anteriormente Jayaprakasha et al. (2003), avaliando a composição do óleo essencial dos galhos desta planta verificaram a presença de hidrocarbonetos $(44,7 \%)$ e compostos oxigenados $(52,6 \%)$. Identificaram-se 27 compostos que constituem $95,98 \%$ do óleo essencial, sendo o acetato de (E)-cinamila $(36,59 \%)$ e (E)-cariofileno $(22,36 \%)$ os compostos majoritários. Estes estudos comprovam que a parte da planta escolhida tem grande importância no que se refere ao teor e composição do óleo essencial.

\section{Zingiber officinale (Gengibre)}

Na Tabela 3 estão descritos os constituintes encontrados no óleo essencial de Zingiber officinale, 
Tabela 1 - Composição química do óleo essencial das folhas de Cymbopogon nardus

\begin{tabular}{lcccc}
\hline \multicolumn{1}{c}{ Compostos } & TR & IRt & IRc & \% \\
\hline Limoneno & 8,133 & 1029 & 1031 & 1102 \\
Linalol & 10,707 & 1095 & 1152 & 0,71 \\
Isopulegol & 12,584 & 1149 & 1158 & 0,96 \\
Citronelal & 12,979 & 1153 & 1230 & 11,07 \\
Citronelol & 16,185 & 1125 & 1255 & 18,56 \\
Geraniol & 17,375 & 1252 & 1271 & 0,75 \\
Geranial & 17,977 & 1267 & 1350 & 1,56 \\
Acetato de citronelila & 21,671 & 1352 & 1357 & 0,69 \\
Eugenol & 21,789 & 1359 & 1379 & 2,59 \\
Acetato de geranila & 22,996 & 1381 & 1392 & 0,80 \\
B-elemeno & 23,395 & 1390 & 1486 & 1,14 \\
Germancreno D & 27,192 & 1485 & 1522 & 0,92 \\
$\delta$ - cadineno & 28,966 & 1523 & 1554 & 4,04 \\
Elemol & 30,016 & 1549 & 1583 & 0,96 \\
Germancreno D-4-ol & 31,084 & 1575 & 1651 & 0,74 \\
Epi- $\alpha$-muurolol & 33,713 & 1642 & 1663 & 1,64 \\
7-epi- $\alpha$-eudesmol & 34,214 & 1663 & & 97,13 \\
Total identificado & & & & \\
\hline
\end{tabular}

$\mathrm{TR}=$ tempo de retenção (minutos), IRt = índice de retençao tabelado $($ Adams, 2007), IRc = índice de retenção calculado, \% = porcentagem do componente

Tabela 2 - Composição química do óleo essencial da casca de Cinnamomum zeylanicum

\begin{tabular}{lcccc}
\hline \multicolumn{1}{c}{ Compostos } & TR & IRt & IRc & $\%$ \\
\hline$\alpha$-pineno & 5,365 & 933 & 939 & 1,13 \\
Canfeno & 5,747 & 954 & 950 & 0,51 \\
Benzaldeído & 5,974 & 960 & 965 & 0,91 \\
$\beta$-pineno & 6,508 & 979 & 979 & 0,77 \\
Limoneno & 8,107 & 1029 & 1031 & 4,66 \\
1,8 -cineol & 8,201 & 1031 & 1035 & 0,99 \\
Linalol & 13,174 & 1095 & 1101 & 0,70 \\
Borneol & 13,402 & 1169 & 1178 & 1,18 \\
Terpinen-4-ol & 13,895 & 1177 & 1184 & 1,73 \\
$\alpha$-terpineol & 14,464 & 1188 & 1225 & 0,57 \\
(Z)- Cinamaldeído & 15,640 & 1219 & 1288 & 77,72 \\
(E)- Cinamaldeído & 18,159 & 1270 & 1290 & 1,11 \\
Acetato de bornila & 18,702 & 1288 & 1451 & 5,99 \\
Acetato de (E)-cinamila & 25,560 & 1446 & & 100,00 \\
Total identificado & & & & \\
\hline
\end{tabular}

TR = tempo de retenção (minutos), IRt = índice de retençao tabelado (Adams, 2007), IRc = índice de retenção calculado, \% = porcentagem do componente 
sendo os compostos majoritários os monoterpenos oxigenados, geranial $(25,06 \%)$, neral $(16,47 \%), 1,8$-cineol $(10,98 \%)$, geraniol $(8,51 \%)$ e acetato de geranila $(4,19 \%)$ e o monoterpeno bicíclico, canfeno (4,30\%).

Foram identificados 57 compostos no óleo essencial de gengibre por Singh et al. (2008), representando 92,7\% da composição total do óleo, sendo geranial $(25,9 \%)$, $\alpha$-zingibereno $(9,5 \%)$, (E,E)- $\alpha$-farneseno $(7,6 \%)$, neral $(7,6 \%)$ e ar-curcumeno (6,6\%), encontrados como componentes majoritários. Estes dados corroboram com aqueles encontrados nesse trabalho para os compostos majoritários (geranial e neral), porém os demais constituintes foram diferentes.

Sacchetti et al. (2004), analisando o óleo essencial de gengibre cultivado na Amazônia equatorial, observaram a presença de zingibereno (23,9\%), $\beta$-bisaboleno $(11,4 \%)$ e $\beta$-sesquifelandreno $(10,9 \%)$, como compostos majoritários, compostos que foram identificados nesse estudo, porém em teores minoritários.

\section{Atividade antibacteriana}

Os valores de CMI dos óleos essenciais obtidos no experimento para as bactérias em estudo estão expressos na Tabela 4. De acordo com estes, verifica-se que os óleos essenciais estudados apresentaram efeito inibitório para bactérias Gram-positivas e para bactérias Gram-negativas, sendo que as bactérias Gram-negativas apresentaram valores de CMI, maiores que as Grampositivas. É possível observar também que dentre as bactérias testadas a espécie Escherichia coli ATCC 11229 apresentou-se como a mais resistente, pois não foi constatado efeito inibitório dos óleos essenciais de C. nardus, e Z. officinale sobre esse microrganismo nas concentrações avaliadas.

Tabela 3 - Composição química do óleo essencial dos rizomas de Zingiber officinale

\begin{tabular}{|c|c|c|c|c|}
\hline Compostos & TR & IRt & IRc & $\%$ \\
\hline 2-heptanol & 4,492 & 896 & 902 & 2,03 \\
\hline$\alpha$ - pineno & 5,376 & 939 & 933 & 1,30 \\
\hline Canfeno & 5,765 & 954 & 951 & 4,32 \\
\hline$\beta$-pineno & 6,700 & 979 & 979 & 0,25 \\
\hline 6-metil-5-hepten-2ona & 6,869 & 985 & 986 & 0,65 \\
\hline Mirceno & 8,146 & 990 & 990 & 1,32 \\
\hline 1,8-cineol & 8,223 & 1031 & 1036 & 10,98 \\
\hline 2-nonanona & 8,519 & 1090 & 1093 & 0,51 \\
\hline Linalol & 10,698 & 1098 & 1102 & 1,80 \\
\hline Citronelal & 12,856 & 1153 & 1154 & 0,73 \\
\hline Borneol & 13,421 & 1169 & 1177 & 1,11 \\
\hline (E) Isocitral & 14,111 & 1180 & 1182 & 0,49 \\
\hline Citronelol & 16,163 & 1225 & 1232 & 2,85 \\
\hline Neral & 16,747 & 1238 & 1246 & 16,47 \\
\hline Geraniol & 17,345 & 1252 & 1258 & 8,51 \\
\hline Geranial & 18,107 & 1267 & 1277 & 25,06 \\
\hline 2-hundecanona & 21,664 & 1294 & 1295 & 0,60 \\
\hline Acetato de geranila & 22,999 & 1381 & 1380 & 4,19 \\
\hline Ar-curcumeno & 27,234 & 1480 & 1483 & 0,55 \\
\hline$\alpha$-zingibereno & 27,801 & 1493 & 1497 & 2,19 \\
\hline E-E- $\alpha$-farneseno & 28,340 & 1505 & 1505 & 1,37 \\
\hline$\beta$-sequifelandreno & 28,976 & 1522 & 1527 & 1,07 \\
\hline Total identificado & - & - & - & 93,24 \\
\hline
\end{tabular}

TR = tempo de retenção (minutos), IRt = índice de retençao tabelado (Adams, 2007), IRc = índice de retenção calculado, \% = porcentagem do componente 
Sabe-se que, na maioria das vezes, bactérias Gram-negativas são menos sensíveis aos óleos essenciais que bactérias Gram-positivas, pois a parede celular das Gram-negativas é rica em polissacarídeos o que inibe a penetração das substâncias antimicrobianas (BURT, 2004).

Dentre os óleos essenciais avaliados, o óleo de capim-citronela apresentou-se menos eficiente. Oussalah et al. (2006), estudando o efeito antimicrobiano de vários óleos essenciais observaram que o óleo essencial de citronela (Vietnam) apresentou valores de CMI de 8,0; 4,0 e $0,5 \mu \mathrm{g} \mathrm{mL}^{-1}$, para E. coli, L. monocytogenes $S$. Thyphimurium e $S$. aureus, respectivamente. A diferença na atividade antimicrobiana pode ter ocorrido devido às diferenças na composição dos óleos essenciais, no diluente utilizado, na cultura de referência e na concentração de células.

Em relação ao efeito do óleo essencial de gengibre no controle de bactérias patogênicas encontradas em alimentos, Singh et al. (2008) empregando o método de difusão cavidade ágar não observaram halos de inibição para $E$. coli e $S$. aureus; resultados similares foram encontrados nesse estudo para E. coli.

Goñi et al. (2009), avaliando o efeito antimicrobiano dos vapores gerados pelo óleo essencial de canela, através de testes de difusão de vapor, encontram os seguinte valores de CMI: $18 \mu \mathrm{g} \mathrm{mL}^{-1}$ para E. coli, $136 \mu \mathrm{g} \mathrm{mL}^{-1}$ para $S$. choleraesuis, $54 \mu \mathrm{g} \mathrm{mL}^{-1}$ para L. monocytogenes, $36 \mu \mathrm{g} \mathrm{mL}^{-1}$ para $S$. aureus, não observando inibição para $P$. aeruginosa. Esses valores são maiores que os encontrados nesse trabalho e essa diferença pode ser atribuída pela diferença da técnica e pela composição da atmosfera que continha $67,12 \%$ de eugenol.

Os óleos essenciais de gengibre e capim-citronela mostraram-se ricos em monoterpenóides, segundo Bakkali et al. (2008) como estes são hidrofóbicos provavelmente irão preferir se deslocar da fase aquosa em direção às estruturas da membrana. O acúmulo dos constituintes dos óleos essenciais na bicamada lipídica da membrana citoplasmática irá conferir a esta uma característica de permeabilidade, promovendo a dissipação da força próton motiva, redução do pool de ATP, do pH interno e do potencial elétrico, e a perda de íons como potássio e fosfato. Esses danos na membrana levam ao comprometimento das suas funções.

Muitos álcoois terpênicos foram identificados na composição dos óleos essenciais de gengibre e capimcitronela, como citronelol, geraniol, $\alpha$-terpineol e o linalol. Pesquisas de Dorman e Deans (2000) inferem que álcoois agem como desidratantes e solventes provocando a desnaturação das proteínas.

Dos óleos em estudo o óleo essencial de canela foi o mais efetivo na inibição do crescimento bacteriano, esse resultado pode estar relacionado com a presença do componente majoritário aldeído cinâmico em elevada concentração $(77,72 \%)$, quando comparada com as outras plantas estudadas. De acordo com Burt (2004), o mecanismo de ação seria, portanto, semelhante a outros aldeídos, que é normalmente considerado como aquele que provoca danos a lipídios e proteínas. Além das perturbações descritas para monoterpenóides, acredita-se que o grupo carbonila é capaz de se ligar às proteínas, impedindo a ação das aminoácido decarboxilases em Enterobacter aerogenes.

\section{Atividade Antioxidante}

Os valores de $\mathrm{CI}_{50}$ dos óleos essenciais obtidos no experimento para a atividade antioxidante dos padrões e óleos essenciais em estudo pelo teste $\beta$ caroteno/ácido linoléico e pelo método de seqüestro de radicais DPPH (1,1-difenil-2-picrilidrazila) estão expressos na Tabela 5 .

Tabela 4 - Concentração mínima inibitória dos óleos essenciais de C. nardus, C. zeylanicum, Z. officinale encontrada para os microrganismos E. coli, S. aureus, L.monocytogenes, P. aeruginosa e S. Cholerasuis

\begin{tabular}{lcccccc}
\hline \multicolumn{7}{c}{ CMI $\left(\mu \mathrm{mL}^{-1}\right)$} \\
\hline Bactéria & Gram & C. nardus & C. zeylanicum & Z. officinale & DMSO & CL \\
\hline S. aureus & + & 31,25 & 7,81 & 7,81 & $\mathrm{NI}$ & 100 \\
L. monocytogenes & + & 31,25 & 7,81 & 15,2 & $\mathrm{NI}$ & 100 \\
E. coli & - & $\mathrm{NI}$ & 15,62 & $\mathrm{NI}$ & $\mathrm{NI}$ & 100 \\
P. aeruginosa & - & 250,0 & 7,81 & 62,5 & $\mathrm{NI}$ & 100 \\
S. Cholerasuis & - & 125,0 & 15,62 & 15,62 & $\mathrm{NI}$ & 100 \\
\hline
\end{tabular}

* NI: não ocorreu inibição 
Tabela 5 - Atividade antioxidante dos óleos essenciais de $C$. nardus, C. zeylanicum, Z. officinale e dos padrões Timol, Ácido ascórbico pelo teste $\beta$-caroteno/ácido linoléico e pelo método de seqüestro de radicais DPPH (1,1-difenil-2-picrilidrazila)

\begin{tabular}{lcc}
\hline \multicolumn{1}{c}{ Métodos } & $\begin{array}{c}\beta \text {-caroteno/ácido } \\
\text { linoléico }\end{array}$ & $\mathrm{DPPH}$ \\
\hline Componentes & $\mathrm{CI}_{50}\left(\mu \mathrm{gLL}^{-1}\right)$ & $\mathrm{CI}_{50}\left(\mu \mathrm{g} \mathrm{mL}^{-1}\right)$ \\
C. nardus & 20,65 & 517,40 \\
C. zeylanicum & 303,56 & $\mathrm{NI}$ \\
Z. officinale & 60,32 & $\mathrm{NI}$ \\
Timol & 20,80 & 45,43 \\
Ácido Ascórbico & 55,72 & 3,32 \\
\hline $\mathrm{CI}_{50}=$ Concentração de inibição de 50\% $\mathrm{NI}=$ não apresentou inibição
\end{tabular}

Pelo método $\beta$-caroteno/ácido linoléico os óleos essenciais em estudo apresentaram atividade antioxidante, sendo que o óleo essencial de C. nardus $\left(\mathrm{CI}_{50} 20,65 \mu \mathrm{g} \mathrm{mL} \mathrm{mL}^{-1}\right)$ apresentou-se mais eficiente, seguido de $C$. zeylanicum e $Z$. officinale. Dentre os padrões testados o timol $\left(\mathrm{CI}_{50} 20,80 \mu \mathrm{g} \mathrm{mL} \mathrm{mL}^{-1}\right)$ se mostrou mais eficiente que o ácido ascórbico.

O método $\beta$-caroteno/ácido linoléico pode ser especialmente útil para as investigações de antioxidantes lipofílicos e é apropriado para a investigação da atividade antioxidante de óleos essenciais. Por outro lado se compostos polares, como o ácido ascórbico, fossem testados apenas por ele seriam considerados como antioxidantes fracos (KULISIC et al., 2004). Este fato explica a menor eficiência do ácido ascórbico quando comparado com o timol.

De acordo com Ruberto e Barata (2000), fenóis são antioxidantes eficientes, assim as moléculas de timol e carvacrol são de fato responsáveis pela atividade antioxidante de muitos óleos essenciais que os contêm. Os álcoois são considerados como a segunda classe de monoterpenos oxigenados, que compõem os óleos essenciais, mais ativas quanto à atividade antioxidante, com ligeira predominância dos alcoóis alílicos como o geraniol. Comparando estes resultados com aqueles encontrados nesse trabalho, pode-se explicar a grande atividade antioxidante do padrão timol e do óleo de capim-citronela que possui como composto majoritário o citronelal, o geraniol e o citronelol, frente ao óleo de canela (que possui como majoritário o aldeído cinâmico), ao óleo gengibre (que é composto majoritariamente pelos aldeídos geranial e neral) e ao padrão ácido ascórbico.

Pelos dados descritos na Tabela 5, observa-se que dentre os óleos essenciais em estudo, o que apresentou maior atividade antioxidante pelo teste do DPPH foi o óleo de citronela $\left(\mathrm{CI}_{50} 517,40 \mu \mathrm{g} \mathrm{mL}^{-1}\right)$, não foi observada atividade antioxidante significativa para os óleos essenciais de canela e gengibre, porém entre os padrões avaliados o ácido ascórbico $\left(\mathrm{CI}_{50} 3,32 \mu \mathrm{g} \mathrm{mL}^{-1}\right)$ mostrou-se mais eficiente que o timol. De acordo com Mata et al. (2007), devido a baixa solubilidade do óleo essencial e seus compostos nas condições do experimento, esse teste não deve ser aplicado para óleos essenciais e sim para compostos hidrofílicos como o ácido ascórbico.

A atividade antioxidante dos óleos essenciais de capim-citronela, cravo da Índia e palmarosa foi evidenciada por Scherer et al. (2009) pelo método de DPPH. Eles observaram que o óleo de cravo-da-índia apresentou uma forte atividade antioxidante, provavelmente por este apresentar como composto majoritário o eugenol $(83,7 \%)$. Nas amostras de citronela tendo como componentes majoritários o citronelal (45\%), geraniol (20,71\%) e citronelol (14,49\%), não foi observada atividade antioxidante significativa. Singh et al. (2007), avaliando o potencial antioxidante de óleos voláteis e oleoresina de C. zeylanicum Blume (folhas e casca), utilizando a técnica de DPPH verificou 52\% de inibição do óleo essencial de canela a uma concentração de $1 \mu \mathrm{L} \mathrm{L}^{-1}$, todos esses estudos discordam dos resultados obtidos nesse estudo.

Estudos de Justo et al. (2008) foram realizados para avaliar as propriedades antioxidantes de extratos ativos de alecrim e gengibre obtidos por extração com fluidos supercríticos. Os resultados obtidos mostraram que entre os extratos orgânicos obtidos, o extrato ativo de gengibre apresentou o maior conteúdo de compostos fenólicos totais $\mathrm{e}$, conseqüentemente, a maior atividade antioxidante, como no óleo essencial de gengibre o teor de fenilpropanoides é pequeno, esse não apresentou atividade antioxidante significativa para a captura de radicais livres.

\section{Conclusões}

1. Os constituintes majoritários encontrados no óleo essencialde Cymbopogonnardus, foramos monoterpenos acíclicos, citronelal (47,12\%), geraniol (18,56\%), e citronelol $(11,07 \%)$; no óleo essencial da casca seca de Cinnamomum zeylanicum foram identificados os fenilpropanóides (E)- cinamaldeído $(77,72 \%)$, acetato de (E)-cinamila $(5,99 \%)$ e o monoterpenóide 1,8-cineol $(4,66 \%)$ e no óleo essencial de Zingiber officinale foram os monoterpenos oxigenados geranial $(25,06 \%)$, neral $(16,47 \%), 1,8$-cineol $(10,98 \%)$, geraniol $(8,51 \%)$, acetato de geranila $(4,19 \%)$ e o monoterpeno bicíclico, canfeno $(4,30 \%)$;

2. Os óleos essenciais apresentaram atividade antibacteriana para bactérias Gram-negativas e para bactérias Gram- 
positivas, com exceção da espécie Escherichia coli ATCC 11229 que apresentou-se como a mais resistente, pois não foi constatado efeito inibitório dos óleos essenciais de C. nardus, e Z. officinale;

3. A atividade antioxidante foi evidenciada pelo teste $\beta$-caroteno/ácido linoléico para $C$. nardus com $\mathrm{CI}_{50}=$ $20,65 \mu \mathrm{g} \mathrm{mL}^{-1}$, para Z. officinale com $\mathrm{CI}_{50}=60,32 \mu \mathrm{g}$ $\mathrm{mL}^{-1}$ e para $C$. zeylanicum com $\mathrm{CI}_{50}=303,56 \mu \mathrm{g} \mathrm{mL}^{-1} \mathrm{e}$ pelo teste do DPPH foi observada apenas para $C$. nardus com $\mathrm{CI}_{50}=517,40 \mu \mathrm{g} \mathrm{mL}^{-1}$.

\section{Agradecimentos}

Ao Conselho Nacional de Desenvolvimento Científico e Tecnológico (CNPQ), a Coordenação de Apoio de Aperfeiçoamento de Pessoal de Nível Superior (CAPES) e a Fundação de Amparo à Pesquisa do Estado de Minas Gerais (FAPEMIG) pela concessão da bolsa de estudos e auxílio financeiro.

\section{Referências}

ADAMS, R. P. Identification of Essential Oils Components by Gas Chromatography/ Mass Spectroscopy. 4. ed. Carol Stream: Allured, 2007. 469 p.

BAKKALI, F. et al. Biological effects of essential oils. Food and Chemical Toxicology, v. 46, n. 02, p. 446-475, 2008.

BLANK, A. F. et al. Influence of season, harvest time and drying on Java citronella (Cymbopogon winterianus Jowitt) volatile oil. Brazilian Journal of Pharmacognosy, v. 17, n. 04, p. 557-64, 2007.

BURT, S. Essential oils: their antibacterial properties and potential applications in foods. International Journal of Food Microbiology, v. 94, n. 03, p. 223-253, 2004.

DORMAN, D. H. J. et al. In vitro evaluation of antioxidant activity of essential oils and their components. Flavour and Fragrance Journal, v. 15, n. 01, p.12-16, 2000.

GOÑI, P. et al. Antimicrobial activity in the vapour phase of a combination of cinnamon and clove essential oils. Food Chemistry, v. 116, n. 04, p. 982-989, 2009.

GUIMARÃES, L. G. L. et al. Influência da luz e da temperatura sobre a oxidação do óleo essencial de capimlimão (Cymbopogon citratus (D.C.) Stapf). Química Nova, v. 31, n. 06 , p. $1476-80,2008$.

JAYAPRAKASHA, G. K. et al. Volatile Constituents from Cinnamomum zeylanicum Fruit Stalks and Their Antioxidant Activities. Journal of Agricultural and Food Chemistry, v. 51, n. 15 , p. $4344-4348,2003$.

JUSTO, O. R. et al. Avaliação do potencial antioxidante de extratos ativos de plantas obtidos por extração com fluido supercrítico. Química Nova, v. 31, n.07, p. 1699-1705, 2008.

KULISIC, T. et al. Use of different methods for testing antioxidative activity of oregano essential oil. Food Chemistry, v. 85, n. 04, p. $633-40,2004$.

LIMA, M. P. et al. Constituintes voláteis das folhas e dos galhos de Cinnamomum zeylanicum Blume (Lauraceae). Acta Amazônica, v. 35, n. 03, p. 363-366, 2005.

LOPES-LUTZ, D. et al. Screening of chemical composition, antimicrobial and antioxidant activities of Artemisia essential oils. Phytochemistry, v. 69, n. 08, p. 1732-8, 2008.

MALELE, R. S. et al. Essential oil of Cymbopogon winterianus Jowitt from Tanzania: composition and antimicrobial activity. Journal of Essential Oil-Bearing Plants, v. 10, n. 04, p. 83-87, 2007.

MARCO, C. A. et al. Características do óleo essencial de capim-citronela em função de espaçamento, altura e época de corte. Horticultura Brasileira, v. 25, n. 03, p.429-32, 2007.

MATA, A. T. et al. Antioxidant and antiacetylcholinesterase activities of five plants used as Portuguese food spices. Food Chemistry, v. 103, n. 03, p. 778-786, 2007.

NATIONAL COMMITTEE FOR CLINICAL LABORATORY STANDARDS. (NCCLS). Methods for Dilution Antimicrobial Susceptibility Tests for Bacteria That Grow Aerobically. 6 ed. Wayne: Clinical and Laboratory Standards Institute, 2003, 65p.

OLIVEIRA, M. M. M. et al. Disinfectant action of Cymbopogon sp. essential oils in different phases of biofilm formation by Listeria monocytogenes on stainless steel surface. Food Control, v. 21, n. 04, p.549-553, 2010.

OUSSALAH, M. et al. Inhibitory effects of selected plant essential oils on the growth of four pathogenic bacteria: $E$. coli $\mathrm{O} 157: \mathrm{H7}$, Salmonella Typhimuruium, staphylococius aureus and Listeria monocytogenes. Food Control, v. 18, n. 05, p. 414-420, 2006.

PEREIRA, A. A. et al. Caracterização química e efeito inibitório de óleos essenciais sobre o crescimento de Staphylococcus aureus e Escherichia coli. Ciência e Agrotecnologia, v. 32, n. 03, p. 887-893, 2008.

RAMALHO, V. C.; JORGE, N.. Antioxidants used in oils, fats and fatty foods. Química Nova, v. 29, n. 04, p. 755-760, 2006.

RUBERTO, G.; BARATTA, M.T. Antioxidant activity of selected essential oil components in two lipid model systems. Food Chemistry, v. 69, n. 02, p. 167-174, 2000.

SACCHETTI, G. Comparative evaluation of 11 essential oils of different origin as functional antioxidants, antiradicals and antimicrobials in foods. Food Chemistry, v. 91, n. 03, p. 621-632, 2004.

SCHERER, R. et al. Composição e atividades antioxidante e antimicrobiana dos óleos essenciais de cravo-da-índia, citronela 
e palmarosa. Revista Brasileira de Plantas Medicinais, v. 11, n. 04, p.442-449, 2009.

SINGH, G. et al. A comparison of chemical, antioxidant and antimicrobial studies of cinnamon leaf and bark volatile oils, oleoresins and their constituents. Food and Chemical Toxicology, v. 45, n. 09, p. 1650-1661, 2007.

SINGH, G. et al. Chemistry, antioxidant and antimicrobial investigations on essential oil and oleoresins of Zingiber officinale. Food and Chemical Toxicology. v. 46, n. 10, p. 3295-3302, 2008.
SOUSA, C. P. Pathogenicity mechanisms of prokaryotic cells: an evolutionary view. Brazilian Journal of Infectious Diseases. v. 07, n. 01, p. 23-31, 2003.

SOUSA, C. M. M. et al. Fenóis totais e atividade antioxidante de cinco plantas medicinais. Química Nova, v. 30, n. 02, p. 351-5, 2007.

TEPE, B. et al. Screening of the antioxidative and antimicrobial properties of the essential oils of Pimpinella anisetum and Pimpinella flabellifolia from Turkey. Food Chemistry, v. 97, n. 04, p. 719-24, 2006 